\title{
The Changes Imposed by the COVID-19 Pandemic in Orthopaedics at the HCD
}

\section{As Mudanças Impostas pela Pandemia COVID-19 no Centro de Ortopedia do HCD}

\author{
Jorge Mineiro ${ }^{1}$, João Cannas² $^{2}$ Luís Barroso², Nuno Lança ${ }^{3}$, João Pedro ${ }^{4}$
}

KEYWORDS: COVID-19; Orthopedic Procedures; Pandemics; SARS-CoV-2

PALAVRAS-CHAVE: COVID-19; Pandemia; Procedimentos Ortopédicos; SARS-CoV-2

With the novel coronavirus COVID-19 outbreak being highly contagious and spread all over the world, it became clear that health care systems globally would need to evolve, develop strategies, identify new models or rejuvenate old conservative methods of care and thus reduce the risk of disease transmission and be prepared for the worse.

In Portugal, both public and private health care systems were together preparing for a disease nobody knew exactly how to handle and the example/scenario we had of its arrival in Europe and progressing west through Italy and Spain was dreadful! In a unique occasion in this country, both private and public health care systems got together to share whatever free beds they had, in particular ICU beds and ventilation facilities taking into account that these were the weakest areas where both the Italian and the Spanish health care systems had failed. But this joint venture was not only for the acute life threatening patients, and the Minister of health issue in mid-March, guidelines advising any organization with facilities to accept and admit patients, to stop all routine activities immediately in order to be prepared to accept COVID-19 positive patients and in a desperate attitude, claimed to assume all costs for these patients affected by this public health condition. At the same time the Portuguese Government declare the lock down for the whole country and together with this, any hospital, public or private, went into a stand still phase that has never happened before. All routine hospital work, out-

1. Professor da Faculdade de Medicina de Lisboa, Lisboa, Portugal; Coordenador do Centro de Ortopedia e Traumatologia do HCD, Lisboa, Portugal. 2. COT - Centro de Ortopedia e Traumatologia do Hospital CUF Descobertas, Lisboa, Portugal.3.FEBOT - Ortopedista do COT diferenciado em Cirurgia da Coluna Vertebral, Lisboa, Portugal. 4. João Pedro, Interno do CHULN, Lisboa, Portugal. 
-patient clinics, all types of exams, hospital admissions and routine operations were cancelled. A very awkward global feeling emerged within the population all of a sudden - hospitals that traditionally were premises where people walked in and felt safe and secure, became places where people were afraid to walk in (74\% of the enquired population $)^{1}$ and 50\% showed anxiety and fear within the hospital!

It became obvious the need to evolve, develop strategies, identify new models to keep in touch with our patients, being aware how concern they were with the news that were being published and publicized on TV, radio and social media every minute and not knowing how long this condition would last. In fine tunning with our organization José de Mello Saúde (JMS), the Orthopaedic Surgeons of the Centro de Ortopedia e Traumatologia, Hospital CUF Descobertas (COT-HCD) started to use all new digital facilities that the JMS developed rapidly, allowing doctors to keep contact with our patients, in particular concerned with those that might need help despite being locked down at home or post-op patients, patients with chronic illnesses, patients undergoing treatment for recent fractures or infections, patients in pain and suffering, etc. In order to facilitate patient's assessment to their own hospital data, MyCUF platform² was developed further to allow patients to book outpatient appointments or exams on line among many other convenient facilities through an easier and friendly way as well as check in and out of the hospital through the net when the lock down is over.

Doctors from the COT-HCD started calling patients that were booked for the outpatient clinics, enquiring if they needed help and if so, an appointment was set up for the patient to be seen avoiding a visit to the emergency department (atendimento permanente). As soon as the telemedicine appointments were set up, 70\% of the department started remote consultations and it was interesting to see that even the nonbelievers became quite enthusiastic with this new tool. With the families at home even the elderly and children, less likely to be acquainted with digital techniques, were being observed - it is amazing, you can see the toddler walking and running and assess the pattern of gait/limp - one colleague was commenting! In a month approximately, 23000 telemedicine appointments were performed in CUF health care system and a survey by JMS showed that 93\% of patients stated that the problem was solved. ${ }^{3}$ For the ones that needed to be seen, the proper protection equipment (PPE) was provided - for doctors and nurses in the clinic, disposable gowns, gloves, masks and visors and for patients, all with surgical masks (for entering the hospital) - and repeated cleaning of the desk top, chairs and handles in the consulting rooms.

At the same time, the COT-HCD kept three teams on call for emergencies as usual - general orthopaedics, hand and wrist and the paediatric orthopaedic team - but the number of cases that were taken to the operating theatre were reduced to a minimum. Although the Hospital CUF Descobertas (HCD) was declared a COVID-19 free hospital and all patients admitted tested negative for COVID-19, but nevertheless routine in the different operating rooms was completely changed and in order to reinforce safety and security it was extremely slowed down and for over a month no routine elective operations were done.

For a couple of weeks, we all in the hospital had to cope not only with staff shortage due to sickness or quarantine, but also with deficiencies in the supply chain in surgical consumers, PPE material and other items that we used routinely in our practice.

Well, six weeks went by and the numbers of deaths and infected patients with COVID-19 have come down to figures that the Portuguese government allowed a gradual come out of the National Lock Down declared in mid-March. Fortunately, the numbers of inpatients admitted to the Portuguese hospitals remained below the expected figures, not only in the general wards but mainly in the intensive care units. Upon realizing that the pandemic was reasonably under control, the Minister of Health changed attitude and abandoned the joint venture with the private sector, claiming that the public hospitals would be able to cope and take all COVID-19 patients and stating that each hospital would have to cover the costs of their own COVID-19 patients, despite realizing that the COVID-19 pandemic is a public health problem usually not covered by private health insurances.

In the first week of May, strategies to come out of the lock down were introduced in each of the private health care units in the whole country and at the HCD, we started planning to resume our hospital activities at the different fronts! Under the guidelines issued by JMS and defining the strategy for de-confinement in out-patient clinics, operating theatres, obstetrics and medical admissions (internal medicine, paediatrics and oncology), the HCD gradually resumed its work.

In the out-patient units, rules that would guarantee security and safety of all patients and staff were established and together with administration-direcção de produção, the ratios of patients to be seen by each doctor and the minimum time for each consultation was 
established in order to make sure that there would be a limited number of patients waiting in the restricted waiting areas and no delays would be accepted from patients or doctors. The number of people in each of the three waiting areas at the COT was calculated taking into account that the number of seats that people could use were marked and spread apart and for this reason, each patient would only be allowed a second person in the consultation if it was a child or a disabled patient. This was not an easy task within the department, taking into account that to examine a hand and wrist will take less time than to examine a hip or a spine, but as it was a question of safety procedures, the 20 minutes established by the JMS guidelines were obviously adopted by all. It was interesting that despite all the concerns, the number of telemedicine consultations in orthopaedics came down drastically and very few patients have been requesting it. It is also a matter of reassurance how the PPE culture is embedded in both groups, patients and professionals, using always all the protective garment required, reinforcing the repeated and frequent cleaning of chairs, desk top and handles and the use of masks for all patients no matter what age. It has been a concern for all staff preventing overcrowding in any area of the department and also the requirement to respect social distancing. Whenever this is not possible, it is reported to the manager and a solution is searched in order to avoid its repetition. But concerned with these issues, recently, JMS took another major step forward developing a facility at the MyCUF platform that would allow patients with out-patient appointments booked, to know the expected time for the consultation, and this information would give them the opportunity to wait outside the waiting areas or even outdoors in the hospital neighbourhood, avoiding crowded spaces.

Regarding the strategy for an operating list, we follow the JMS and international guidelines ${ }^{4}$ for resuming routine elective operating in orthopaedics and trauma. We have to separate two different contexts of NON-COVID surgical patients - in-patient and out-patient. The latter are less of a concern, because they are usually healthier, younger and surgical procedures are shorter requiring no admission into the hospital (only into the day surgery unit). Our main concern regarding in-patients is to guarantee availability of ICU beds if needed on a daily basis, taking into account the pandemic has not ended and that we may need them for other purposes. Our second concern is that elective surgery should be risk-stratified ${ }^{5}$ and possibly certain cases deferred, based upon a patient's age (>75 years), morbid obesity, diabetes, uncontrolled-hypertension, chronic pulmonary disease, obstructive sleep apnea, chronic heart disease and immunocompromised state. Specifically, for major surgery in orthopaedics such as hip or knee arthroplasty and spinal deformities procedures, the need for beds in ICUs for these procedures can be $19 \%$ or higher. ${ }^{6}$ According to one study, patients that may require admission to ICU includes those with congestive heart failure, obstructive pulmonary disease, procedures with high blood loss such as revision hip arthroplasty, chronic, major spine surgery and body mass index $>35 \mathrm{~kg} / \mathrm{m}^{2}$ and therefore elective surgery at this stage of the pandemic should be started with the healthier patients and experience amassed from establishing screening, prevention, and treatment protocols.?

Apart from these requirements our operating lists at present are shorter, allowing 60 to 120 minutes between finishing wound closure and the skin incision on the next patient. Certain requirements that are time consuming are strictly followed, as limiting the number of persons in the operating room in particular during intubation-induction and extubation-waking up from a general anaesthetics and throughout the procedure, reducing the number of door openings, putting on and off all the PPE garment required in the operating room taking into account that all necessary tools (X-rays machinery, navigation consoles, arthroscopy towers, robots, etc...) should be kept to a minimum in the room and set at the very beginning and surfaces of all equipment in the operating room (including computers, lead gowns, X-rays machinery, etc...) should be wiped down after each case. ${ }^{5}$

From the anaesthetic point of view whenever possible, the preferred technique would be a type of regional anaesthesia like a peripheral block, spinal anaesthesia in order to avoid the risky manipulation of the patient's airway.

From a technical point of view, Orthopaedics and Traumatology are a type of high risk surgeries due to the fact that they are aerosol generating procedures (AGP). ${ }^{8}$ Most of our procedures do generate large amount of aerosol particles that can be inhaled or get into your eyes as surgeon or as a member of the surgical team, if appropriate protection gear is not used like P2 masks, goggles and visors, double gloving and water proof long gowns. Aware of the AGP from many of the high-power tools we use, whenever possible we follow the international guidelines of keeping the power setting of our surgical tools to as low as possible - and these are tools like powered bone reamers, high speed pneumatic drills, pneumatic saws, electrocautery, etc..., or as an alternative we use the old fashion hammer and chisel, gigli saw, manual bone reamers, etc... As far as wound closure is concern, whenever possible, I use absorbable sutures avoiding 
unnecessary visits to the out-patient clinic to have the stitches or staples removed soon after the procedure.

In the post-operative period we try to discharge patients as soon as possible and it is interesting that patients do accept it - it is extremely distressing and hard to go through an operation that requires hospital admission and not to be able to have the comfort of a visitor (family or friend) to cheer you up or to chat during the long days after the operation. But these are the universal rules we follow for the safety of those that are in the hospital beds and that we do not want to get contaminated by others from the outside world. We have reinforced the telemedicine nursing services post-op, checking the progress of the patients and enquiring about any queries they may have, contact that are similar to the ones done routinely in the Day Surgery Unit follow ups.

However, there is a lot more that can be done in order to avoid hospital visits during the most vulnerable period after an operation. Telemedicine consultation can help us a great deal and we should explore this route further and give our patients better quality of life. Another area that should be developed is home physiotherapy with rehabilitation programs and protocols of virtual or augmented reality for the more common procedures like total knee or hip arthroplasty and guided by experienced physiotherapists.

These are early results from what we have learned from the COVID-19 pandemic in our own hospital up to now. However, the pandemic has not ended yet and this is evolving every day, therefore what is our best practice today, based on the little evidence that exists, may not be the same tomorrow and you have to be prepared for that. From a professional point of view this requires a continuous education for all health care professionals and close contact with the Infectious Control Committee in order to be updated. We follow the guidelines form our own organization JMS, that has been an example of the front runners against the COVID-19 in this country always concerned not only with patients but also with its own healthcare professionals, and we should also follow the national guidelines of the Portuguese Government regarding the different stages of the deconfinement in this country.

The world has changed faster than we expected over the last three months and we should now try to catch up and integrate all the new digital developments and learn how to make the most of it for the sake of protection of our patients and of all health care professionals and preparedness for the next pandemic.

\section{ACKNOWLEDGEMENTS/ AGRADECIMENTOS}

I would like to thank Dr. Edla Pires from Direção de Marketing JMS, for the inspiration and support writing this article.

\section{ETHICAL DISCLOSURES}

CONFLICTS OF INTEREST: The authors have no conflicts of interest to declare.

FINANCING SUPPORT: This work has not received any contribution, grant or scholarship.

PROVENANCE AND PEER REVIEW: Not commissioned; externally peer reviewed.

\section{RESPONSABILIDADESÉTICAS}

CONFLITOS DE INTERESSE: Os autores declaram a inexistência de conflitos de interesse na realização do presente trabalho.

FONTES DE FINANCIAMENTO: Não existiram fontes externas de financiamento para a realização deste artigo.

PROVENIÊNCIA E REVISÃO POR PARES: Não comissionado; revisão externa por pares.

\section{REFERENCES}

1. Universidade Católica Portuguesa. Inquérito realizada pelo CESOP-Universidade Católica Portuguesa para a RTP, Público e parceiros e patrocinadores da Universidade. Foi realizado entre os dias 6 e 9 de abril de 2020. Lisboa: UCP; 2020.

2. José de Mello Saúde. MyCUF [accessed May 2020] Available from: https://www.cuf.pt/clientes-e-acompanhantes/my-cuf.

3. José de Mello Saúde. Inquérito de Satisfação a Clientes de Teleconsulta da CUF - abril 2020. Lisboa: JMS; 2020.

4. Mouton C. Hirschmann MT, Ollivier M, Seil R, Menetrey J. COVID-19 - ESSKA guidelines and recommendations for resuming elective surgery. Version 2. J Exp Orthop. 2020;7:28. doi: 10.1186/s40634-020-00248-4.

5. Parvizi J, Gehrke T, Krueger CA, Chisari E, Citak M. Van Onsem $\mathrm{S}$, et al. Resuming elective orthopaedic surgery during theCOVID-19 pandemic: guidelines developed by the international consensus group (ICM) [accessed May 2020] Available from: http://dx.doi.org/10.2106/JBJS.20.00844.

6. O'Connor CM, Anoushiravani AA, DiCaprio MR, Healy WL, Iorio R. Economic Recovery After the COVID-19 Pandemic: Resuming Elective Orthopedic Surgery and Total Joint Arthroplasty. J Arthroplasty. 2020 (in press). doi: 10.1016/j. arth.2020.04.038

7. American College of Surgeons. Joint statement: roadmap for resuming elective surgery after COVID-19 pandemic [accessed April 2020] Available from: https://www.facs.org/covid-19/clinical-guidance/roadmap-elective-surgery.

8. Iyengar KP, Jain VK, Vaish A, Vaishya R, Maini L, Lal H. Post COVID-19: Planning strategies to resume orthopaedic surgery-challenges and considerations. Version 2. J Clin Orthop Trauma. 2020 May 4;11(Suppl 3):S291-5. doi: 10.1016/j. jcot.2020.04.028. 